\title{
Genotoxicity of Momordica charantia Extract in Swiss Albino Mice (Mus musculus)
}

\author{
Adewumi O. O. ${ }^{1}{ }^{*}$, Oladele E. O. ${ }^{1}$ and Taiwo I. A. ${ }^{2}$ \\ ${ }^{1}$ Biology Unit, Distance Learning Institute, University of Lagos, Akoka, Lagos State, Nigeria \\ ${ }^{2}$ Department of Cell Biology and Genetics, University of Lagos, Akoka, Lagos State, Nigeria \\ Corresponding Author: *oluadewumi@unilag.edu.ng
}

\begin{abstract}
The study aims at determining the safety of Momordica charantia (Bitter melon) for use by diabetic patient. This study was carried out to ascertain the genotoxic potential of Momordica charantia in mice using the micronucleus assays. A total of forty (40) laboratory albino mice weighing between 20 and 25 grams were obtained from the Zoological garden, University of Lagos. The mice were in eight groups comprising of five animals each. The doses of the extract administered were $50 \mathrm{mg} / \mathrm{kg}$, $100 \mathrm{mg} / \mathrm{kg}$ and $150 \mathrm{mg} / \mathrm{kg}$ per body weight and the route of administration was oral by gastric gavages using a metal canula. The control groups $A$ and $B$ were fed with distilled water for 14 and 28 days respectively. The other groups were also treated with a daily dose of the extract for 14 and 28 days at different concentrations. The mutagenic potential of Momordica charantia was assessed with reference to the frequency of micronucleated polychromatic erythrocytes (MNPCE) in polychromatic erythrocytes (PCE) in the bone marrow of mice. During sacrifice, the bone marrow cells were collected from the femur and smeared on slides. For each mouse, polychromatic erythrocytes (PCE) were scored for the number of micronucleated polychromatic erythrocytes $(M N P C E)$ and the percentage was calculated. The frequencies of MNPCE/PCE were $0.17 \pm 0.09 \%$ and $0.13 \pm 0.02 \%$ in the control group for 14 days and 28 days respectively, $0.33 \pm 0.12 \%$ and 0.30 $\pm 0.08 \%$ in the $50 \mathrm{mg} / \mathrm{kg}$ group, $0.38 \pm 0.06 \%$ and $0.34 \pm 0.09 \%$ in the $100 \mathrm{mg} / \mathrm{kg}$ group, and 0.24 $\pm 0.08 \%$ and $0.35 \pm 0.05 \%$ in the $150 \mathrm{mg} / \mathrm{kg}$ group. The results showed a significantly increased frequency of micronucleated polychromatic erythrocytes for the three doses administered. The results were considered statistically significant at $p<0.05$. This indicates a warning signal to careless and indiscriminate use of the drug by humans.
\end{abstract}

Keywords: Genotoxicity, Micronucleus, Extract, Micro nucleated, Polychromatic erythrocytes

\subsection{Introduction}

Momordica charantia (MC) is commonly known as Bitter gourd, Bitter melon and Balsam pear. It is also identified as Bitter cucumber in the United States of America; Paroka in France and Kakle in East Africa. It is an annual herbage plant that belongs to the family Cucurbitaceae. Originally, it was found in the tropics but can now be found in most regions of the world and is usually seen on fences and shrubs (Grover and Yadav, 2004). It is an economically important edible medicinal plant that is cultivated all around the world especially in tropical areas. It is a plant that is composed of multifaceted range of beneficial compounds. These compounds include bioactive chemicals, vitamins, minerals and antioxidants which all makes it versatile in treating a wide range of illnesses (Chaturvedi et al., 2004). Seeds, fruits, leaves, and root of this plant have been used in traditional medicine for microbial infections, sluggish digestion, menstrual stimulation, wound healing, inflammation, fever reduction, hypertension, and as a laxative. However, clinical conditions in which Momordica charantia extracts (mainly from the fruit) are presently being used include diabetes, dyslipidemia, microbial infections, and potentially as a cytotoxic agent for certain types of cancer (Chaturvedi et al., 2004). Momordica charantia contains biologically active chemicals that include glycosides, saponins, alkaloids, fixed oils, triterpenes, proteins and steroids. The immature fruits are a good source of vitamin $\mathrm{C}$, vitamin $\mathrm{A}$, vitamin $\mathrm{E}$, vitamins $\mathrm{B}_{1}, \mathrm{~B}_{2}, \mathrm{~B}_{3}$, as well as vitamin $\mathrm{B}_{9}$ (foliate), phosphorus, and 
iron (Liu et al., 2009). The medicinal value of bitter melon has been attributed to its high antioxidant properties (Budrat and Shotipruk, 2008; Myojin, et al., 2008). This is because the herb contains phenols, flavonoids, isoflavones, terpenes, anthroquinones, and glucosinolates, all of which contribute to its bitter taste (Snee et al., 2011).

Over the years, medicinal plants have been recognized to be of great importance to the health of individuals. The use of herbs for the management of different illnesses is gaining grounds because it is cheap and readily available. Herbal preparations have however been in use before the onset of pharmaceutical products and their use has increased in recent times. One of the commonest applications of the use of herbal extracts is in the control of blood glucose in diabetics. Different extracts have been reportedly used for the treatment of hyperglycemia. Mormordica charantia has been reported to be the most popular plant used worldwide to treat diabetes (Maries and Famsworth, 1995; Aloulou et al., 2012, Hfaiedh et al., 2013). There are several reviews by different authors about anti-diabetic herbal plants (Ayodhya et al., 2010; Malviya et al., 2010; Patel et al., 2012). Extracts from different parts of Momordica charantia have been reported to have a wide medicinal use in the traditional medical systems, most often as hypoglycemic and anti-diabetic agents (Ahmed et al., 2001; Grover and Yadav, 2004). The glucose-lowering activity of $M$. charantia administered as both fresh juice and unripe fruit has been well documented in animal models of diabetes (Grover et al., 2002). Momordica charantia has been used in expelling intestinal gas, promoting menstruation, wound treatment, rheumatism, malaria and vaginal discharge while its seeds are used to induce abortion (Taylor, 2005; Sofowora, 2006). It can also be used in treating heart diseases, measles, rheumatism, small pox, chicken pox, gastrointestinal disorder, gonorrhea as well as malignant ulcers and periodical pains.

In vivo and in vitro studies have shown that some natural constituents of plant parts (fruits, leaves, roots) play a modulating role in xenobiotic effects (Roncada et al., 2004). Some herbs might be pharmacologically and clinically effective; they are not necessarily free of toxicity and side effects. Therefore, investigation into this traditionally used medicinal plant is valuable as a source for potential chemotherapeutic drugs. This study therefore sought to investigate the genotoxicity potential of Momordica charantia in mice using the micronucleus assay.

\subsection{Materials and Methods}

\subsection{Test animals}

Forty (40) albino mice weighing between 20 grams to 25 grams of both sexes were obtained from the Botanical and Zoological garden, Department of Zoology, University of Lagos. The animals were kept under standard laboratory conditions and allowed to acclimatize for two weeks. The animals were fed ad libitum with access to food and water.

\subsection{Test chemical}

\subsubsection{Determination of plant extract concentration}

This was done using the gravimetric method. Three evaporating dishes, A, B and C were obtained and weighed. Each dish was heated on a burner and weighed again. About $1 \mathrm{ml}$ of Momordica charantia extract was pipetted into each of the dishes: A, B and C and then weighed again. The evaporating dishes containing the extract were heated on a burner until the extract became dry and concentrated. The dishes were finally weighed and the various weights in grams were taken.

The concentration of the extract was calculated using the formula:

Concentration in $\mathrm{g} / \mathrm{ml}=$ average weight of dry extract on evaporating dish

Concentration in $\mathrm{mg} / \mathrm{l}=$ concentration of extract in $\mathrm{g} / \mathrm{ml} \times 1000$

\subsubsection{Preparation of aqueous extracts}

The fresh leaves of Momordica charantia were purchased from the local market and washed thoroughly with water. The plant materials were sorted out to eliminate all extraneous substances. The clean Momordica charantia leaves were air dried for 5 days and the dried plant materials were processed to fine powder with a laboratory mill (Weston manual miller) and stored in air and water- 
tight containers at room temperature until needed. The water extract was prepared using $30 \mathrm{~g}$ portion of the powder dissolved in $500 \mathrm{ml}$ of distilled water and was soaked for 4 days. The resultant liquid was filtered using a funnel plugged with a cheese cloth to remove the coarse fibers. The solution was later refrigerated for further use.

\subsection{In-vivo exposure experiment}

The animals were divided into eight (8) groups of 5 rats per group. The dose of the extract administered was $50 \mathrm{mg} / \mathrm{kg}, 100 \mathrm{mg} / \mathrm{kg}$ and $150 \mathrm{mg} / \mathrm{kg}$ body weight and the route of administration was oral by gastric gavages using a metal cannula. Animals in Groups A and B (control) were fed with distilled water for 14 and 28 days respectively. The other groups were treated with a daily dose of Momordica charantia aqueous extract for 14 and 28 days at different concentrations. Administration of the extract was done orally using a cannula to inject the extract.

\subsection{Micronucleus (MN) assay}

The Micronucleus (MN) Assay detects damage of the chromosome or mitotic apparatus of cells. Cells from the bone marrow, polychromatic erythrocytes (PCEs), are examined to visualize the MN, which may form under normal conditions. The assay is based on an increase in the frequency of micro nucleated PCEs in the bone marrow of treated mice. The preparation and staining of bone marrow cells were carried out according to Schmid (1976) and Hayashi et al. (1994). The experimental animals were sacrificed. The dissected femurs were opened and Foetal Bovine Serum was used to flush bone marrow cells from both femurs into Eppendorf tubes and cells were centrifuged at 6000 rpm for 5 minutes and the supernatant discarded. The pellet was re-suspended in a drop of serum for slides preparation. The cells were smeared on glass slides and air-dried and later immersed in methanol for 10 minutes and then stained with 5\% Giemsa in Sorenson's buffer ( $\mathrm{pH}$ 6.9) for 20 minutes and counter stained with May-Grunwald for 5 minutes. After dehydration through graded alcohol and clearing in xylene, slides were mounted in DPX (Distyrene, plasticizer and xylene). From each slide, about 1000 erythrocyte cells/animal were scored under the light microscope with plane objective at 100/1.25 oil mount magnification, for micronuclei in polychromatic erythrocytes (MNPCE) and normochromic erythrocytes (MNNCE). The PCE: NCE ratio in every 1000 cells counted was analyzed.

\subsection{Statistical analysis}

The micronucleus assay were carried in three replicates and results were subjected to one-way analysis of variance (ANOVA) and the Tukey-Kramer multiple comparison test using the Graph Pad Instat software (version 3.01). The results were considered statistically significant at $p<0.05$.

\subsection{Results}

\subsection{Induction of micronuclei}

For each mouse, polychromatic erythrocytes (PCE) were scored for the number of micro nucleated polychromatic erythrocytes (MNPCE) and the percentage calculated. The percentage of PCE per 1000 blood cells is given in Table 1. Values shown are means \pm standard deviations for five (5) mice per dose (in three replicates).

There was a significant induction of $\mathrm{MN}$ in the erythrocytes of exposed mice group at different concentrations of the extract as compared with their respective control groups (Figure 1 and Table 1). The treatments and sample days, the percentage of PCEs having MN and the percentage polychromatic erythrocytes (PCEs) per 1000 cells are shown. All animals survived to terminal sacrifice. As seen in Table 1, the MN assay of Momordica charantia. L extract revealed that for all the doses tested, the MNPCE frequency was increased and, in most cases, doubled. The frequencies of MNPCE/PCE were $0.17 \pm 0.09 \%$ and $0.13 \pm 0.02 \%$ in the control group for 14 days and 28 days respectively, $0.33 \pm 0.12 \%$ and $0.30 \pm 0.08 \%$ in the $50 \mathrm{mg} / \mathrm{kg}$ group, $0.38 \pm 0.06 \%$ and $0.34 \pm 0.09 \%$ in the $100 \mathrm{mg} / \mathrm{kg}$ group, and $0.24 \pm 0.08 \%$ and $0.35 \pm 0.05 \%$ in the $150 \mathrm{mg} / \mathrm{kg}$ group. The highest concentrations of the extract show significant induction of $\mathrm{MN}$ than their respective control groups. The significant highest $\mathrm{MN}$ frequency was observed in the $100 \mathrm{mg} / \mathrm{kg}$ concentration $(0.38 \pm 0.06)$ and 
the least MN frequency was observed at the $150 \mathrm{mg} / \mathrm{kg}(0.24 \pm 0.08)$. Generally, with increasing concentrations and exposure duration, the $\mathrm{MN}$ frequency increases.

Table 1: Effect of Momordica charantia in micronucleus formation in mice bone marrow cells

\begin{tabular}{|l|l|l|l|}
\hline \multirow{2}{*}{ Treatments/ Exposure Days } & \multicolumn{2}{|c|}{ MNPCEs } & $\%$ PCE per $1000 \quad$ cells \\
\cline { 2 - 3 } & Number & \%MNPCE & \\
\hline Control (Distilled Water) & & & \\
14 Days & 21 & $0.17 \pm 0.09$ & $43.3 \pm 6.75$ \\
28 Days & 16 & $013 \pm 0.02$ & $40.3 \pm 3.79$ \\
\hline Extract $50 \mathrm{mg} / \mathrm{kg}$ & & & \\
14 Days & 40 & $0.33 \pm 0.12^{*}$ & $40.5 \pm 3.26$ \\
28 Days & 37 & $0.30 \pm 0.08^{*}$ & $39.4 \pm 3.56$ \\
\hline Extract $100 \mathrm{mg} / \mathrm{kg}$ & & & \\
14 Days & 46 & $0.38 \pm 0.06^{*}$ & $36.5+123$ \\
28 Days & 41 & $0.34 \pm 0.09^{*}$ & $37.5 \pm 5.22$ \\
\hline Extract $150 \mathrm{mg} / \mathrm{kg}$ & & & \\
14 Days & 29 & $0.24 \pm 0.08$ & $34.7 \pm 4.07$ \\
28 Days & 43 & $0.35 \pm 0.05^{*}$ & $36.2 \pm 3.50$ \\
\hline
\end{tabular}

* Significantly different to the negative control (Tukey-test, $p<0.05$ )

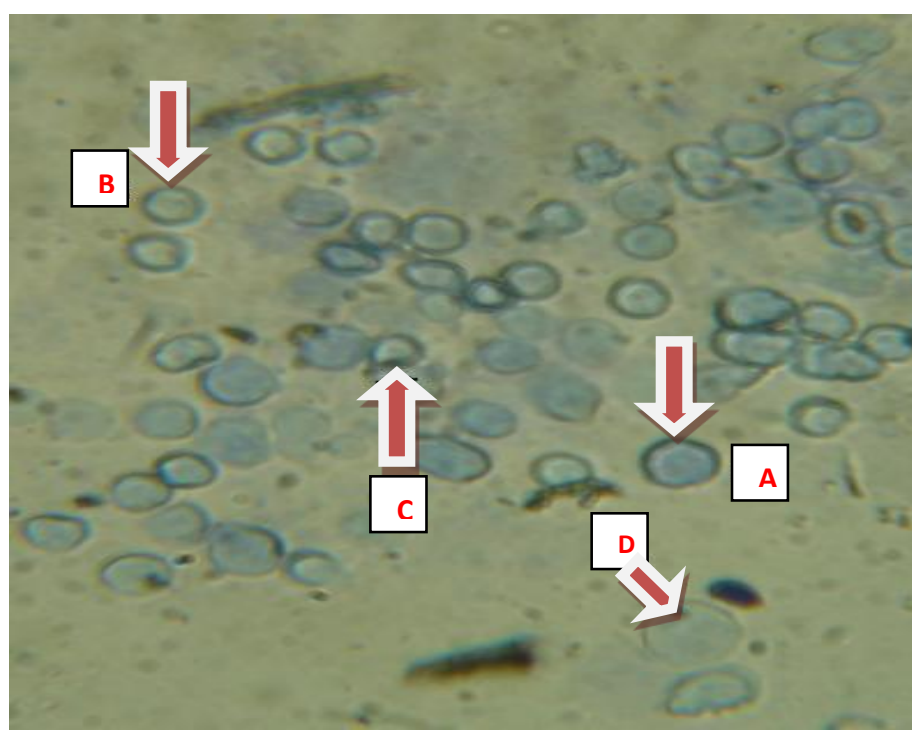

Figure 6: Effect of Momordica charantia on micronucleus assay: A-Polychromatic Erythrocyte BNormochromatic Erythrocyte, C-Micronuclei in Polychromatic Erythrocyte, D-Micronuclei in Normochromatic Erythrocyte (x100)

For genetic toxicology studies, the formation of micronucleus in bone marrow and peripheral blood erythrocytes is recognized as one of the established methods for in vivo cytogenetic assays (Fenech, 2000). Micronuclei are formed in anaphase by chromosomal fragments or fagging chromosomes not included in the nucleus of the daughter cells. Micronuclei have been observed in plants and in numerous tissues of many animal species. Presently, micronuclei serve as an important endpoint to detect the genetic damage by chemicals or radiation in cultured cells and organisms (Heddie et al., 1983).

The micronucleus assay using small laboratory animals is considered the best-documented in vivo assay for chromosome aberrations (clastogenic effects) in relation to the number of tested chemicals (Morita et al., 1997). The mouse bone marrow micronucleus test is one of the several available in vivo mammalian test systems for the detection of chromosomal aberrations. The evaluation of micronucleus frequencies in mice remain one of the primary genotoxicity tests for product safety assessment. In this study, the MNPCE frequency was increased and, in most cases, doubled. An increase in the frequency (percentage) of micronucleated polychromatic erythrocytes (MNPCEs) in treated animals is an indication of induced chromosomal damages in mouse bone marrow cells. According to Krishna and Hyashi (2000), decrease in the PCE: NCE ratio due to either direct cytotoxicity or micronuclei formation and heavy DMA damages as observed in this present study in the lowest concentration of the extract, usually lead to cell death or apoptosis. However, Sumanth and 
Chowdary (2010) in their study had a contrary opinion that Momordica charantia is devoid of genotoxic potential due to no significant variation in the total number of chromosomal aberrations; considering the $\mathrm{P} / \mathrm{N}$ ratio when its anti-mutagenic activity was evaluated. The values observed in the micronucleus assay in this study must have arisen from loss of chromosomal fragments during the division of the nucleated precursor cells as stated by Salamone et al. (1980). The micronucleus results from this study, suggest that Momordica charantia extract could produce some aneugenic effects on erythrocyte precursors cells. Therefore, Momordica charantia is capable of inducing aneugenic and clastogenic effects in exposed mice. Research using animal model of diabetes has demonstrated that MC extracts increase glucose utilization by the liver (Sarkar et al., 1996), decrease gluconeogenesis through the inhibition of two key enzymes (glucose-6-phosphatase and fructose-1, 6-bisphosphatase), and improve glucose oxidation by activating glucose-6-phosphaie dehydrogenase (Shibib et al., 1993). Extracts of MC also enhance cellular uptake of glucose, promote insulin release (Welihinda et al., 1982) and increase the number of insulin producing beta cells in the pancreas of diabetic animals (Ahmed et al., 1998). Usually, medicinal plants are the potential sources of bioactive agents. Bitter melon extracts have also been shown to inhibit growth and proliferation of various types of cancer cells in animals (Kwatra et al., 2013). Other research indicate MC extracts is able to modify the immune response in cancer patients via decreased intestinal secretion of interleukin-7, reduced lymphocyte number and increased T-helper and natural kilter cell populations (Manabe et al., 2003) safety measure for the continued use of medicinal plants (Verschaeve et al., 2004). This is often induced by clastogenic substances in dividing cells such as bone marrow. A simpler approach to assess chromosome damages in vivo is to measure the micronucleus (Fenech, 2000). Micronuclei frequencies have been considered to be a reliable index for detecting chromosome breakages and loss (Lajmanovich et al., 2005).

\subsection{Conclusion}

Over the years, researchers have verified the traditional uses of this bitter plant that is known as important natural remedy for various diseases. This present study draws our attention to the genotoxic capacity of bitter melon. The results of this current study demonstrated that bitter melon though with anti-diabetic effects such as, decreasing serum glucose concentration, increasing serum insulin level, increasing glucose uptake by the peripheral tissues and decreasing intestinal glucose absorption could be genotoxic at higher doses. However, it is clearly shown in this study that bitter melon can induce mutagenic and genotoxic effects in animal models. These indicate a warning signal to injudicious and indiscriminate use of the plant by humans. This observed genotoxicity can possibly occur in humans taking more than the required dosage or using Momordica charantia for a very long period of time. It is remarkable that bitter melon can cure diabetes and fight off a wide range of illnesses but can be seen to have side effects like genotoxicity as shown in this study. However, despite the abundance of scientific studies on the benefits of bitter melon, there is still need for several evidences on the longterm safety of the bitter melon consumption. Therefore, being cautious of the dosage and route of administration is important.

\section{References}

Ahmed I., Adeghate E. and Sharma, A. K. (1998). Effects of Momordica charantia fruit juice on islet morphology in the pancreas of the streptozotocin-diabetic rat. Diabetes Research and Clinical Practice, 40, pp. 145-151.

Ahmed I., Lakhani, M. S. Gillett, M. John, A. and Raza, H. (2001). Hypotriglyceridemic and hypocholesterolemic effects of anti-diabetic Momordica charantia (karela) fruit extract in streptozotocin induced diabetic rats. Diabetes Research and Clinical Practice, 51(3), pp. 155-161.

Aloulou, A., Hamden, K., Elloumi, D., Ali, M. B., Hargafi, K., Jaouadi, B., et al. (2012). Hypoglycemic and antilipidemic properties of kombucha in alloxan-induced diabetic rats. $B M C$ Complementary and Alternative Medicine, 12, pp. 12-63.

Ayodhya, S., Kusum, S. and Anjali, S. (2010). Hypoglycaemic activity of different extracts of various herbal plants. International Journal of Research in Ayurveda and Pharmacy, 1(1), pp. 212-224. 
Budrat, P. and Shotipruk, A. (2008). Extraction of phenolic compounds from fruits of bitter melon (Momordica charantia) with subcritical water extraction and antioxidant activities of these extracts. Chiang Mai Journal of Science, 35(1), pp. 123-30.

Chaturvedi, P., George, S., Milinganyo, M. and Tripathi, Y. B. (2004). Effect of Momordica charantia on lipid profile and oral glucose tolerance in diabetic rats. Phytotherapy Research, 18, pp. 954-956.

Fenech, W. (2000). The in vitro micronucleus technique. Mutation Research, 445, pp. 81-95.

Grover, J. K., Yadav, S. and Vats, V. (2002). Medicinal plants of India with anti-diabetic potential. Journal of Ethnopharmacology, 81, pp. 81-100.

Grover, J. K., and Yadav, S. P. (2004). Pharmacological actions and potential uses of Momordica charantia: a review. Journal of Ethnopharmacology, 93, pp. 123-132.

Hayashi, M., Tice, R. R., Macgregor, J.T., Aderson, D. and Blakey, D. H. (1994). In vivo rodent Erythrocytes micronucleus assay. Mutation Research, 312, pp. 293-304.

Heddie, I. A., Hite, M., Kirkhart, B., Mavourmin, K., MacGregor, J. T., et al. (1983). The induction of micronuctei as a measure of genotoxicity. A report of the US Environmental Protection Agency Gene-Tox Program. Mutation Research, 123, pp. 61-118.

Hfaiedh, M., Brahmi, D. and Zourgui, L. (2014). Hepatoprotective effect of Taraxacum officinale leaf extract on sodium dichromate-induced liver injury in rats. Environ Toxicol. 31, pp. 339-349.

Krishna, G. and Hyashi, M. (2000). In vivo rodent micronucleus assay: protocol, conduct and data interpretation. Mutation Research, 455, pp. 155-166.

Kwatra, D., Subramaniam, D., Ramamoorthy, P., Standing, D., Moran, E., Velayutham, R., et al. (2013). Methanolic extracts of bitter melon inhibit colon cancer stem cells by affecting energy homeostatsis and autophagy. Evidence-based Complementary and Alternative Medicine.

Lajmanovich, R. C., Cabagna, M., Peltzer, P. M., Stringhini, G. A. and Attademo, A. M. (2005). Micronucleus induction in erythrocytes of the Hyla pulchella tadpoles (Amphibia: Hylidae) exposed to insecticide endosulfan. Mutation Research, 587, pp. 67-72.

Liu, J., Chen, J. Wang, C. and Qui, M. (2009). New Cucurbitane Triterpenoids and Steroidal Glycoside from Momordica charantia. Molecules, 14, pp. 4804-4813.

Malviya, N., Jain, S. and Malviya, S. (2010). Anti-diabetic potential of medicinal plants. Acta Poloniae Pharmaceutica, 67(2), pp. 113-118.

Manabe, M., Takenaka, R. Nakasa, T. and Okinaka, O. (2003). Induction of anti-inflammatory responses by dietary Momordica charantia I. (Bitter gourd). Bioscience, Biotechnology and Biochemistry, 67, pp. 2512-2517.

Maries, R. J. and Famsworth, N. R. (1995). Antidiabetic plants and their active constituents. Phytomedicine, 2, pp. 137-189.

Morita, T., Asano, N., Awogi, T., Sasaki, Y.F., Sato, S., et al. (1997). Evaluation of the rodent micronucleus assay in the screening of I ARC carcinogens (groups 1, 2A and 2B). The summary report of the 6th collaborative study of the micronucleus group test. Mammalian mutagenicity study group. Mutation Research, 389, pp. 3-122.

Myojin, C., Enami, N., Nagata, A., Yamaguchi, T., Takamura, H., et al. (2008). Changes in the radical-scavenging activity of bitter gourd (Momordica charantia L.) during freezing and frozen storage with or without blanching. Journal of Food Science, 73(7), pp. 546-550. 
Patel, P., Harde, P., Pillai, J., Darji, N. and Patel, B. (2012). Antidiabetic herbal drugs - a review. Pharmacophore, 3(1), pp. 18-29.

Roncada, T., Vicentinii, V. E. P. and Mantovani, M. S. (2004). Possible modulating actions of plant extracts on the chromosome breaking activity of MMC and Ara-C in human lymphocytes in vitro. Mutation Research, 18, pp. 617-622.

Salamone, M., Heddle, J. Stuart, E. and Kate, M. (1980). Towards an improved micronucleus test. Mutation Research, 74, pp. 347-356.

Sarkar, S., Pranava, M. and Marita, R. (1996). Demonstration of the hypoglycemic action of Momordica charantia in a validated animal model of diabetes. Pharmacological Research, 33, pp. 14.

Schmid, W. (1976). The micronucleus test for cytogenetic analysis. In Hollaender, A. (ed.), Chemical Mutagens, Principles and Methods for their detection, 4. Plenum Press, New York, pp. 31-55.

Shibib, B. A., Khan, L. A. and Rahman, R. (1993). Hypoglycemic activity of Coccinia indica and Momordica charantia in diabetic rats: depression of the hepatic gluconeogenic enzymes glucose 6phosphatase and fructose-1, 6 bisphosphatase and elevation of both liver and red-cell shunt enzyme gtucose-6-phosphate dehydrogenase. Journal of Biochemistry, 292, pp. 267-270.

Snee, L. S., Nerurkar, V. R., Dootey, D. A., Efird, J. T., Shovic, A. C., et al. (2011). Strategies to improve palatability and increase consumption intentions for Momordica charantia (bitter melon): A vegetable commonly used for diabetes management. Nutrition Journal, 10, pp. 78.

Sofowora, A. (2006). Medicinal Plants and Traditional Medicine in Africa. 2nd Ed., Spectrum Books Ltd., Ibadan, Nigeria, pp. 151-153, 209-214.

Sumanth, M and Chowdary, G. N. (2010). Antimutagenic activity of aqueous extract of Momordica charantia. International Journal for Biotechnology and Molecular Biology, 1(4), pp. 42-46.

Taylor, L. (2005). Bitter Melon: Herbal Properties and Actions. In: The Healing Power of Rainforest Herbs, Taylor, L. (Ed.). Square One Publication Inc., New York, ISBN-13: 9780757001444, pp: 1-5.

Verschaeve, L., Kestens, V., Taylor, J. L. S., Elgorashi, E. E., Maes. A, Van, L., et al. (2004). Investigation of the Antimutagenic effects of selected South African medicinal plant extracts. Toxicology In Vitro 18(1), pp. 29-35.

Welihinda, J., Arvidson, G., Gylfe, E., Hellman, B. and Karlsson, E. (1982). The insulin releasing activity of the tropical plant. Momordica charantia Acta Biology Med Ger Pub Med. 41(12), pp. 1229-1240. 